\title{
Nanomechanical Analysis of Hybrid Silicones and Hybrid Epoxy Coatings-A Brief Review
}

\author{
Atul Tiwari \\ Department of Mechanical Engineering, University of Hawaii at Manoa, Honolulu, USA \\ Email: tiwari@hawaii.edu
}

Received October 13, 2011; revised November 27, 2011; accepted December 9, 2011

\begin{abstract}
This review article is written on the investigations of nanomechanical properties of coatings by using nanoindentation techniques. The focus is on the studies that were conducted on epoxy polymer, silicones and their hybrid materials. The article describes a large number of developmental studies that are conducted on coatings. Materials properties such as nanoindentation hardness, modulus, scratch, wear and viscoelastic behavior have been described. Moreover, the article summarizes various studies that mention the use of different nanoparticles in coating formulations that could improve the mechanical strength and service life span of the coatings. The mode and mechanism of material's failure has been outlined and discussed.
\end{abstract}

Keywords: Silicone; Epoxy; Coatings; Nanoindentation; Nanoscratch; Viscoelastic

\section{Introduction}

The strength of conventional polymers can be evaluated using a universal testing machine operating in tensile or compressive mode. The thin coatings or films that cannot be removed from the substrate can be tested using the nanoindentation technique. The use of indentation technique to determine the mechanical properties of materials was realized in late 1950 [1]. During a nanoindentation test, a nanoindenter head of known geometry is pressed into the surface with a predefined load or depth of penetration and the resultant affected area is recorded. The ratio of load over area determines the value of nanoindentation hardness. The basic nano-mechanical properties obtained from the nanoindentation tests are elastic modulus and indentation hardness of the material. Several nanoindentation test methods are available that can determine fracture toughness, creep, storage and loss modulus, yield stress, as well as interfacial and surface adhesion. Similarly, the tribological behavior of surfaces, such as a scratch or mar resistance, friction coefficients, and wear performance can be obtained [2].

A wide variety of coated and bare substrates have been tested in past few decades. The mechanism of deformation of soft coating on hard substrates [3], hard coatings on soft substrates [3-5], soft coating on soft substrates [6,7], or hard coating on hard substrates [8], have been broadly established. Several review articles, have been written on the nanoindentation techniques so far [9-14] but none of them focused on hybrid silicone or hybrid epoxy coatings. This review summarizes the nanomechanical studies that are reported on hybrid silicone and epoxy coatings.

\section{Theory}

This section briefly describes the theoretical concepts associated with the instrumented nanoindentation technique (IIT). Standard IIT equipment (Figure 1) consists of three basic components: an actuator to apply force, an indenter mounted to a rigid column through which the force is applied on the sample and a sensor that measures the displacement of the indenter [15].

IIT equipment can generate required forces electromagnetically using either coils and magnets or capacitors that have fixed and moving plates. In some cases, the piezoelectric actuators can be used to generate small forces. The indenters used in IIT are selected according to the information that is being collected. The indenter may have pyramidal, spherical, cube corner or conical geometry. A pyramidal shaped Berkovich indenter is most common in acquiring the nanomechanical data. The displacement in IIT can be recorded using capacitive sensors.

\subsection{Nanoindentation Curve}

A wide variety of coated substrates can be tested using the IIT. Properties of the coatings are normally influenced by the underlying substrates. However, the nano-mechanical 


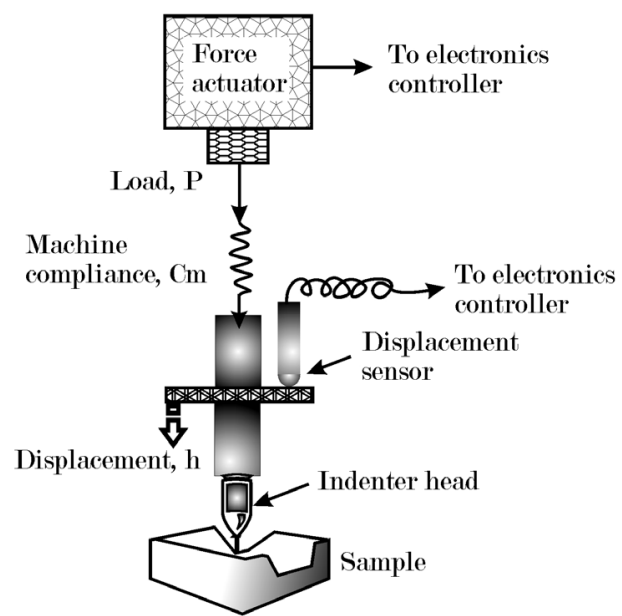

Figure 1. A typical nanoindenter setup for the mechanical properties measurement of coatings.

properties of the coated material are least affected by the substrate when determined from the $10 \%$ of the thickness of the coating $[13,16]$. In a typical nanoindentation experiment, the indenter makes contact with the material surface and then penetrates to a depth or load. A nanoindentation curve is plotted for load as a function of displacement of the indenter and shows loading and unloading pattern (Figure 2). Any inconsistency observed in the curve indicates cracking, delamination or another failure in the coating. Figure 2 shows the unloading process and parameters associated with the contact geometry. The depth of penetration is considered to be displacement into the sample. The hardness and modulus values are determined as discussed in following section.

\subsection{Hardness and Young's Modulus Analysis}

The load and displacement curve can be used to determine the hardness and elastic modulus of the material [17]. The hardness $H$ of the material is determined by dividing maximum load $P_{\max }$ by the projected contact area $A$ of the indenter at maximum load as shown in Equation (1).

$$
H=\frac{P_{\max }}{A}
$$

For ideal indenter geometry (Figure 3 ), the projected contact area, A can be determined from the contact depth $h_{c}$ at maximum load $P_{\max }$ such as in Equation (2).

$$
A=c_{0} h_{c}^{2}
$$

The value of $c_{0}$ depends on the indenter tip. For example, the value of $c_{0}$ is 24.5 for the Berkovich pyramidal diamond tip. In the load vs displacement curve, the contact depth $h_{c}$, is different from maximum indentation depth $h_{\max }$ at the maximum load due to the elastic deformation of the area around the indenter head. The contact

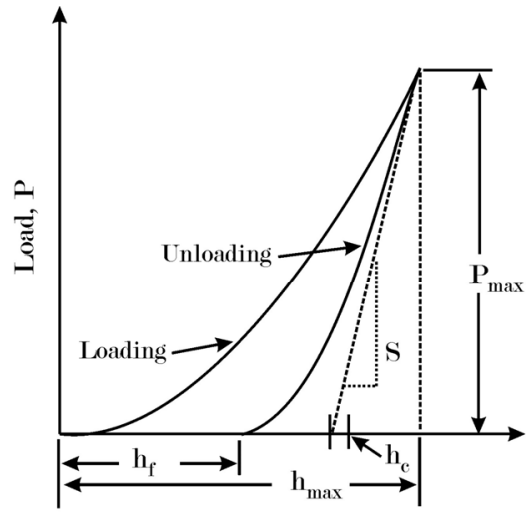

Displacement, $\mathrm{h}$

Figure 2. Typical nanoindentation loading and unloading curve.

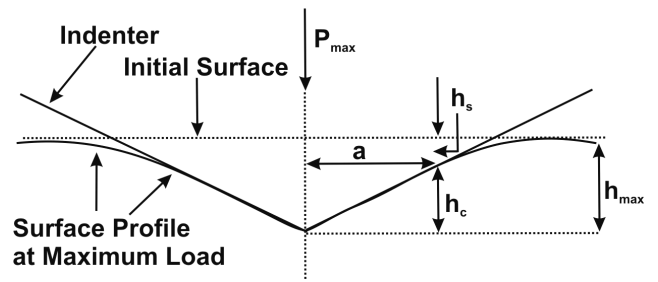

Figure 3. Schematic of an ideal conical indenter at maximum load.

depth is given in Equation (3).

$$
h_{c}=h_{\max }-\varepsilon \frac{P_{\max }}{S}
$$

where, $S$ represents stiffness that can be calculated from the slope of the unloading curve at the maximum load. The value of $\varepsilon$ is 0.75 for the pyramidal indenter.

The calibration of indenter shape is critical in determining the hardness of the material. Fused quartz silica is used for the calibration of indenter tip because the mechanical properties of the fused quartz are known. The stiffness $S_{\max }$ is obtained from load-depth curves and assuming that the elastic modulus of the fused quartz is constant, the projected contact area $A$ can be obtained as a function of stiffness $S_{\max }$ as given in Equation (4).

$$
A=\left(\frac{\pi}{4}\right)\left(\frac{S_{\max }}{E_{r}}\right)^{2}
$$

where $E_{r}$ is the reduced modulus, which represents the elastic deformation occurring both in the sample and indenter. The value $E_{r}$ can be calculated from Equation (5).

$$
\frac{1}{E_{r}}=\frac{1-v_{s}^{2}}{E_{s}}+\frac{1-v_{i}^{2}}{E_{i}}
$$

where $E_{s}$ is the elastic modulus of the fused quartz silica, $E_{i}$ is the elastic modulus of the indenter, $v_{s}$ is the Pois- 
son's ratio of the fused quartz silica and $v_{i}$ is the Poisson's ratio of the indenter. The projected area $A$ that was calculated using Equation (4) can be plotted as a function of the contact depth $h_{c}$. The area function $A\left(h_{c}\right)$ so obtained is a fifth order polynomial that can be represented as Equation (6).

$$
A=c_{0} h_{c}^{2}+c_{1} h_{c}+c_{2} h_{c}^{1 / 2}+c_{3} h_{c}^{1 / 4}+c_{4} h_{c}^{1 / 6}+c_{5} h_{c}^{1 / 8}
$$

where $c_{0}, c_{1}, c_{2}, c_{3}, c_{3}$ are constant that can be determined by curve fitting of the measured area function $A\left(h_{c}\right)$.

The elastic modulus $E_{s}$ of the material can be determined using Equations (5) and (7). The $v_{\mathrm{s}}$ in Equation (5) is taken as Poisson's ratio of the test material.

$$
E_{r}=\frac{\mathrm{d} p}{\mathrm{~d} h} \frac{1}{2} \frac{\sqrt{\pi}}{\sqrt{A}}=S \frac{1}{2} \frac{\sqrt{\pi}}{\sqrt{A}}
$$

\subsection{Scratch Tests}

The coating performance depends on its ability to resist mars and scratches. Researchers have proposed several techniques and test methods; however, none of them are as precise as the nanoscale scratch testing, which uses an instrumented nanoindenter. The scratch test helps determine the mechanism that causes the deformation of materials as well as the delamination of coatings.

In a typical scratch experiment, a ramp load is applied to an indenter head in the normal direction as it simultaneously moves on the sample surface in a lateral direction. The instrument controls the normal force and lateral displacement of the indenter, while the lateral force and normal displacement are recorded as a function of time. Critical information such as the coefficient of friction, cross profile topography, residual deformation and pileup of material during the scratch can be obtained as a function of scratch distance.

\subsection{Dynamic Mechanical Properties}

The viscoelastic behavior of coatings can also be investigated using nanoindentation technique [18]. The stressstrain relationship of the materials displaying linear viscoelastic properties under sinusoidal loading is shown in Equation (8):

$$
\sigma=\varepsilon_{o} E^{\prime} \sin \omega t+\varepsilon_{o} E^{\prime \prime} \cos \omega t
$$

where $\sigma$ is the stress, $\varepsilon_{o}$ is the strain amplitude, $\omega$ is the angular frequency and $t$ is the time elapsed. Rearranging Equation (8) we get Equations (9) and (10):

$$
E^{\prime}=\frac{\sigma_{o}}{\varepsilon_{o}} \cos \phi
$$

and

$$
E^{\prime \prime}=\frac{\sigma_{o}}{\varepsilon_{o}} \sin \phi
$$

where $\sigma_{\mathrm{o}}$ is the stress amplitude, $\phi$ is the phase lag between stress and strain and $E^{\prime}$ and $E^{\prime \prime}$ are storage and loss modulus respectively. The term $E^{\prime}$ represents the capacity of material to store energy, a component that is in phase with the applied load or displacement. The term $E^{\prime \prime}$ represents the capacity of material to dissipate energy, a component that is $90^{\circ}$ out of phase with the applied load or displacement. The ratio $E^{\prime \prime} / E^{\prime}$ represents $\tan \phi$, also called loss factor, and is used to measure the damping characteristic of a linear viscoelastic material. The value of $E^{\prime}$ and $E^{\prime \prime}$ can be used to calculate the complex modulus through the Equations (11) and (12):

$$
\begin{gathered}
E=E^{\prime}+i E^{\prime \prime} \\
|E|=\sqrt{E^{\prime 2}+i E^{\prime \prime 2}}
\end{gathered}
$$

In order to determine the value of $E^{\prime}$ and $E^{\prime \prime}$ from a dynamic nanoindentation experiment, the equipment supplies a controlled load to the indenter head that sets the load amplitude, while the displacement amplitude and phase angle are measured [19]. At each test site, the indenter head contacts the material's surface. The indenter vibrates at a certain frequency, and the resulting response is measured. The contribution of instrument to the total response is then subtracted to determine the response from the material.

\section{Background and Literature Survey}

The nano-mechanical properties of coatings can be influenced by the coated substrate, so it is wise to consider the indentation data when the indenter penetration depth is approximately $10 \%$ of the coating thickness. When a coating is subjected to an indentation experiment, several different types of damage may occur as the load on the indenter increases. For example, the coating may delaminate due to a loss of contact between the coating and its substrate or brittle coatings may fracture. These failures can be used to determine the fracture strength, toughness as well as residual stresses of both the coating network and its interface with the substrate.

\subsection{Investigations on Epoxy Based Coatings}

The epoxy resin based coatings have been used for a long time on a wide variety of substrates. These coatings have a tendency to adhere to the substrate through mechanically created anchoring sites. The large polymeric chains in such coating composition allow formulators to accommodate desired pigments and fillers. However, such polymer coatings consist of defect sites such as pinholes, holidays and cavities that enable the diffusion of mois- 
ture which in turn lead to premature failure of the material. Considerable research has been conducted on such coatings. The proceeding paragraphs describe the studies conducted on an epoxy coating using IIT.

Davies et al. [20] studied the nano-mechanical behavior of epoxy adhesive joints with varying thicknesses that were bonded to aluminum substrates. They used the nanoindentation technique to understand different aspects associated with the joint interphase such as modulus of the joints and substrate/adhesive. They found that the modulus value drops from $70 \mathrm{GPa}$ corresponding to the aluminum substrate to $2 \mathrm{GPa}$ corresponding to the adhesive layer. Authors however, concluded that nanoindentation studies were insufficient to monitor the presence of the interface region between the adhesive and substrate.

Shi et al. [21] added $1 \mathrm{wt} \%$ nanoparticles of $\mathrm{Zn}, \mathrm{SiO}_{2}$, $\mathrm{Fe}_{2} \mathrm{O}_{3}$ and halloysite clay in a commercial epoxy resin. The authors noticed that the epoxy coating containing $\mathrm{SiO}_{2}$ nanoparticles displayed significant enhancement in Young's modulus measuring up to approximately 2.5 GPa compared to $250 \mathrm{MPa}$ in pristine epoxy coating. However, the other modified nanoparticle coatings did not show enhancement in the stiffness value. Similarly, approximately $30 \%$ of an increment in Young's modulus was obtained for nano- $\mathrm{Zn}$ modified epoxy coating while the nano- $\mathrm{Fe}_{2} \mathrm{O}_{3}$ and nanoclay modified coatings showed a $25 \%$ to $30 \%$ decrease in Young's modulus value compared to that of the unmodified epoxy coating.

In another study, Woo et al. [22] investigated the residual mechanical properties of epoxy-organoclay nanocomposites after they were exposed to moisture and UV light. They recorded an increase of up to $8 \%$ in flexural modulus upon adding $5 \mathrm{wt} \%$ organo-clay, but the flexural modulus decreased gradually with an increase in time of exposure to moisture. Similarly, the tensile modulus increased with the incorporation of clay, but the strength and failure strain decreased due to clay aggregates, voids and different cure kinetics affected by the presence of organoclay. Also, tensile strength decreased after $250 \mathrm{~h}$ of UV light exposure. Their micro-hardness experiment suggests that hardness increased with embrittlement, but after UV light exposure, the nanoindentation modulus decreased systematically.

Li et al. [23] analyzed epoxy resin containing various percentages of coiled carbon nanotubes and single-walled carbon nanotubes using the nanoindentation technique. They found that the hardness and modulus values of nanocompsites increased with the increase in nanotube concentration. Additionally, it was seen that the hardness and elastic modulus was consistent for different concentration of carbon nanotubes, indicating a uniform dispersion of carbon nanotubes in nanocomposite. Similarly, Kardar et al. [24] synthesized an epoxy acrylate resin containing different multifunctional acrylate monomers cured under UV radiation. Suspension of nano-alumina in tripropyleneglycoldiacrylate was also added to the formulation. The resulting nanocomposites were investigated using nanoindentation and nanoscratch techniques. They found that nanocomposites containing nano-alumina displayed less hardness and increased elastic behavior compared to that of pristine resin.

Addition of nanoparticles in the coating formulation reportedly improves the scratch resistant of the coating. For example, Wu et al. [25] incorporated colloidal silica in the coating formulation that was prepared with 3-glycidoxypropyltrimethoxysilane, tetraethylorthosilicate and ethylenediamine (EDA). The cross-linking density, hardness, fracture toughness and elastic modulus were increased on addition of EDA and colloidal silica. Also, authors found that pencil hardness could be increased from $2 \mathrm{~B}$ to $5 \mathrm{H}$ by increasing the number of layers and thickness of the coating.

In another study, coating formulations were prepared by reacting diglycidyl ether of bisphenol-A (DGEBA) and isophorone diamine. The coating was modified with nanoalumina, silanized nanoalumina, and organo-modified montmorillonite nanoclay. Authors found that nanoindentation hardness value increased marginally on addition of nanoparticles. Moreover, a significant improvement in wear index was achieved in case of coating formulations containing grafted alumina and nanoclay. The nanoscratch was generated with the cantilever operating in atomic force microscopy mode. A significant improvement in scratch resistant was notice in the modified coatings [26]. Similarly, thin pristine epoxy coating was applied on aluminum surface and tested using Berkovich nanoindenter (Figure 4). The scanning electron microscopy (SEM) was used to understand various modes of failures in the coating [27].

The wear resistance of epoxy nanocomposite coating containing nano- $\mathrm{TiO}_{2}$ and other organic fillers was studied

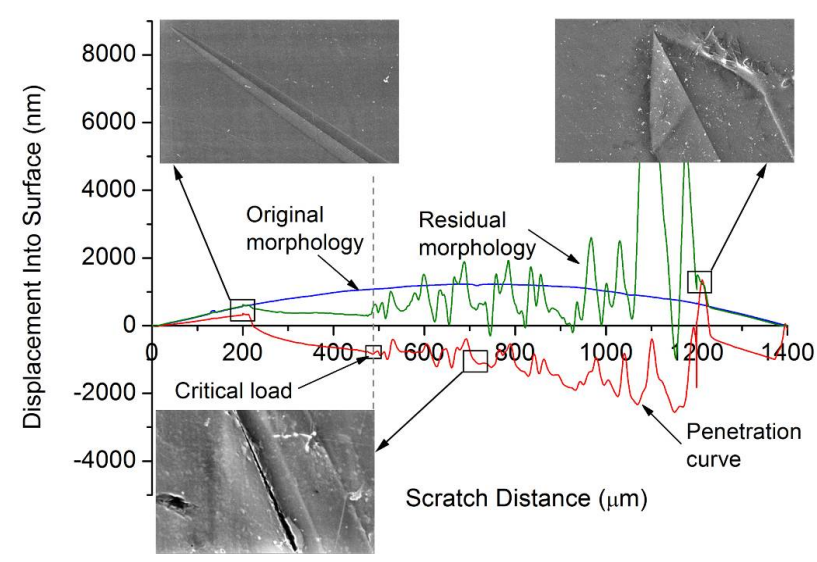

Figure 4. Nanoscratch analysis of pristine epoxy coating. The SEM images are showing initiation, propagation and termination stages in the nanoscratch testing [27]. 
by Chang et al. [28-30]. Authors found that addition of nano- $\mathrm{TiO}_{2}$ reduces the friction coefficient but increased the wear resistance and load bearing capacity.

The visco-elastic properties of epoxy nanocoatings containing nanosilica were studied by Zhang et al. [31, 32]. The volume fraction of nanosilica in nanocoatings was varied between 1 to $14 \mathrm{wt} \%$. The changes in viscoelastic properties of nanocoatings as a function of nanoparticle concentration, frequency and penetration load were recorded. Authors found that storage modulus of the material increased with the frequency and concentration of nanofiller. The loss tangent on the other hand displayed initial increment followed by decreasing behavior with frequency. It was postulated that there is a critical frequency value that corresponds to the glass transition temperature of the material. Moreover, the loss tangent was not affected by the nanofillers but the matrix. In another study that was conducted on pristine epoxy and nano- $\mathrm{TiO}_{2}$ modified epoxy coatings, the storage modulus remained unaffected of nanofillers (Figure 5). The loss modulus however, increased slightly with frequency that was possibly due to higher loading rate [27].

\subsection{Investigations on Hybrid Silicone Coatings}

Hybrid materials that contain higher organic branching points for crosslinking reactions displayed higher $\mathrm{H}$ values than do linear polymers [33]. In a study, the reduced modulus, and reduced hardness varied through the different layers of the coating [34]. High value of reduced modulus and reduced hardness were recorded at the surface due to a condensed morphology. Lower values were recorded in the bulk due to a porous structure while values increased again at the coating-metal interface due to a denser structure [34,35].

In hybrid coatings, compositions with higher organic content cause segregation in the network, resulting in high-silica regimes surrounded by hydrocarbon-rich regimes. These coating networks displayed different mechanical properties than did the pristine silica network. A silica-rich coating based on tetraethoxysilane (TEOS) display near elastic behavior while a hybrid glycidoxypropyltrimethoxysilane (GTMS) coating displayed increased penetration on loading and almost complete recovery during unloading. The TEOS coating showed the smallest amount of creep due to a densely packed, rigid silica network while the creep was higher for the GTMS coating due to the viscoelastic flow and relaxation processes associated with the long chain hydrocarbon-rich domains. Young's modulus also decreased with the increase in organic portion in the backbone of the coating structure. In fact, the modulus of GTMS was 25 times less than that of TEOS [36].

The nanomechanical properties were determined on quasi-ceramic high-silicone content coatings (QC) that were aged for three months on three different aluminium alloy substrates (Figure 6). The hardness and modulus values were determined as a function of displacement into the coatings. The average hardness values for the QC-coated 2024Al, 6061Al and 7075Al were $0.42 \mathrm{GPa}$, $0.41 \mathrm{GPa}$ and $0.47 \mathrm{GPa}$, respectively while the average modulus values were $4.40 \mathrm{GPa}, 4.51 \mathrm{GPa}$ and $5.45 \mathrm{GPa}$, respectively. The loading-and-unloading curves demonstrate the elastic recovery of the coatings with negligible plastic deformation. The average hardness of uncoated alloys 2024Al, 6061 Al, and 7075Al were $1.87 \mathrm{GPa}, 1.47$ $\mathrm{GPa}$ and $2.37 \mathrm{GPa}$, respectively, while the average moduluses were $77 \mathrm{GPa}, 76 \mathrm{GPa}$ and $78 \mathrm{GPa}$, respectively. The slight variation in the mechanical properties of the QC coatings on different surfaces suggests that the coating may have been influenced to a small degree by the substrate mechanical properties or due to the solubilised alloying elements from the substrate alloy [37,38].

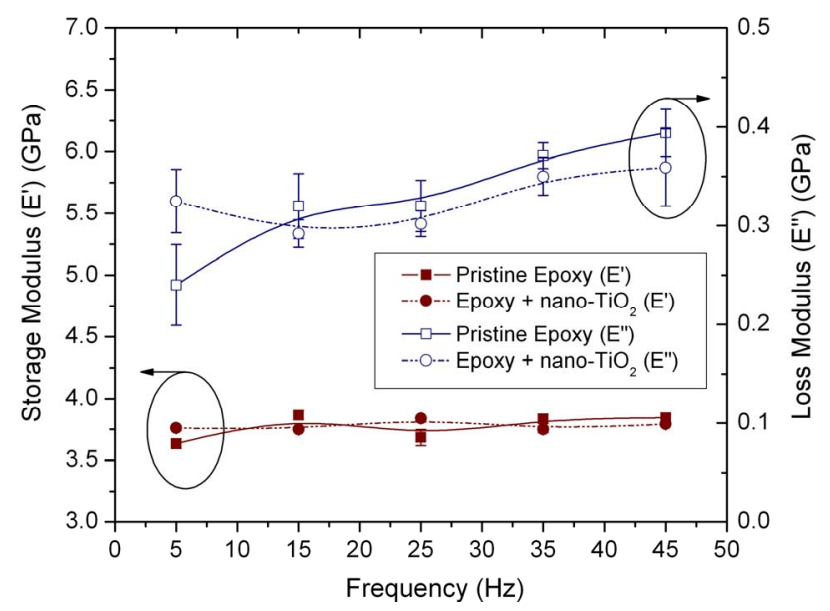

Figure 5. Dynamic nanoindentation based visco-elastic properties of pristine epoxy and epoxy nano- $\mathrm{TiO}_{2}$ coating [27].

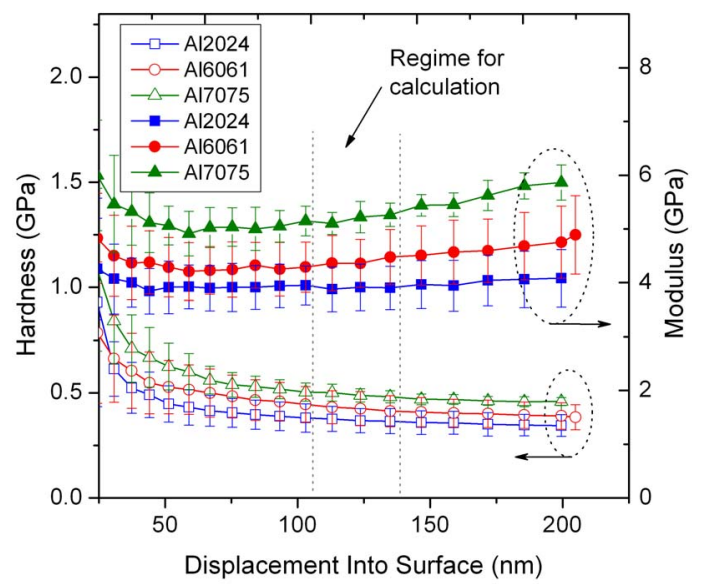

Figure 6. Nanoindentation of hybrid silicone coating showing hardness and modulus values [38]. 
In another nanomechanical scratch test, cracks grew in a silicone ceramer (CR) coating on a $6061 \mathrm{Al}$ substrate due to the propagation of the indenter head. The coating cracks were perpendicular to the direction traversed by the indenter head. The length of the cracks increased in proportion to the force on the indenter and to the penetration of the nanoindenter through the thickness of the coating. Delamination and peeling occurred when the load on the indentation head exceeded the force required to hold the molecular segments in the coating. The results indicate that the degree of plastic deformation in the coating was limited, which is characteristic of the highly cross-linked coating [39].

Coatings applied on substrates can display lower mechanical properties with elevated-temperature curing if ions from the substrate diffuse and accumulate in the coating, modifying its structure. Residual stress values suggest that the coatings are put under stress when the substrate restricts coating contraction due to shrinkage. Additionally, the higher coefficient of thermal expansion of the coating compared to that of the substrate contributes to more residual tensile stresses after cooling. Coatings containing photo-curable groups have shown compressive residual stresses with UV light curing, suggesting that the effect of shrinkage due to drying is much less than with UV curing [40].

Mirabedini et al. [41] studied the silicone elastomer coatings containing $\mathrm{TiO}_{2}$. They investigated the effect of $\mathrm{TiO}_{2}$ on the modulus, hardness, tensile strength and abrasion resistance of resultant silicone elastomer coating. They also studied the effect of $\mathrm{TiO}_{2}$ on the adhesion strength of the coating that acted as a top layer. The results were correlated with the mechanical properties of silicone elastomer coating. They found that the incorporation of $\mathrm{TiO}_{2}$ pigment affected the mechanical properties of the resultant coating. The changes in the properties were a function of the volume fraction of the incorporated pigment. The increase in pigment loading resulted in an increase in the elastic modulus, hardness, tensile strength and abrasion resistance. Similarly, the energy required to break the coating increased. However, there was a decrease in the elongation at fracture. An increase of approximately $15 \%$ was observed in mechanical properties except the hardness increment was only marginal. The adhesion strength of the coating also increased with the increase in pigment concentration to $10 \mathrm{wt} \%$, possibly due to an increase in cohesive strength as a result of an increase in tensile strength and modulus values. However, the adhesive strength of the coating reduced when the concentration of $\mathrm{TiO}_{2}$ increased beyond $10 \mathrm{wt} \%$, probably, because of the agglomeration of the pigment at a higher loading.

Tanglumlert et al. [42] prepared a hard coating suspension to improve the scratch resistance of poly- methylmethacrylate surface. A coating solution was formulated by reacting silatrane with GTMS in the presence of an acid catalyst. They found that the scratch resistance of the coated surface increased with the increase in alkoxysilane content in the coating. They also discovered that the curing time and curing temperature affected the scratch resistance and adhesion properties of the coating layer.

Similarly, Antanacio et al. [43] measured mechanical properties and adhesive strength of hybrid sol-gel coating. They found that an increase in the chain length of the organic modifier resulted in an increase in the hardness and elastic modulus of the final film. Cracking characteristics of the coating dropped due to the increase in flexible linkage as a result of an organic modifier. The toughness value of organically modified coating decreased due to a lower Young's modulus, while the adhesion improved. They proposed that the organosilane in the coating composition contributed to the dissipation of the energy required for cracking due to a large cohesive zone and the ability of the film to deform visco-elasticcally at high strains.

Etienne-Calas et al. [40,44] studied two different organic-inorganic coatings on silicone and glass substrates. They prepared the coatings through a sol-gel procedure and deposited them on substrates using the spin coating technique. The first coating composition was formulated using methyltrimethoxysilane, colloidal silica and TEOS, while the second composition was based on 3-(trimethoxysilyl) propyl-methacrylate. At lower loads, authors determined the coating hardness and modulus values from indentation curves. At higher load values, propagation of cracks were used to determine the coating toughness, residual stress and interface toughness, while energey analysis was used to study chipping and delamination in the coating. It was also found that mechanical properties of the coatings were influenced by the rapid diffusion of the sodium ions into the coating from the glass substrate.

Esfandeh et al. [45] reported a study on the adhesion behavior of several silicone modified epoxy coatings. A three layered coating assembly of approximately $200 \mu \mathrm{m}$ were applied on a 1050 aluminum alloy. The effect of different silanes on the adhesive strength of the coating was studied using a pull-off test and a scanning electron microscope. Based on their observations of gel time, failure mode and adhesive strength, authors concluded that the coating assembly consisting of 50/50 siliconeepoxy ratio in the intermediate layer displayed the best results among the compositions. Scanning electron micrographs and immersion experiments in sea water confirmed the excellent adhesion of the layered coating on the aluminum surface.

Kohl et al. $[46,47]$ tested two sets of duplex coatings 
each with the same topcoat but different bond coats over steel panels. Nanoindentation and scratch tests were performed on the coating of thickness between $65 \mu \mathrm{m}$ and $485 \mu \mathrm{m}$. It was also discovered that the topcoat layer had an indentation modulus of $2.7 \mathrm{MPa}$ and irrecoverable energy of $11 \%$. Similarly, one bond coat displayed an indentation modulus of $3.9 \mathrm{MPa}$ with $9 \%$ irrecoverable energy, while the other bond coat showed an indentation modulus of $155 \mathrm{MPa}$ with $54 \%$ irrecoverable energy. Fracture mechanics and inelastic deformations of the coatings were also studied. Critical tensile stress that was required for tearing off the coating was used to develop a theoretical model. The model predicted the critical value of load when the failure occurred.

Kozuka et al. [48] studied the changes in residual stress on alkoxide-derived silica and titania films coated on the glass substrates. It was seen that residual tensile stress increased with the increase in the curing temperature of the coating. Also found that the cracking tendency of the coating decreased as the thickness increased and the heating rate decreased. Interestingly, it was realized that adding an organic polymer to the coating composition helped create a crack free coating.

Kim et al. [49] prepared the coating compositions by reacting vinyl terminated polydimethylsiloxane with tetrakis(dimethylsiloxy)silane in the presence of a platinum-divinyltetramethylsiloxane complex. Authors have used a statistical, experimental design, to study the effect of different chemical constituents on resultant shear stress in the coatings. It was noticed that the modulus of the coating varied with the thickness of the coating and that the shear rate was dependent on the modulus of the coating.

Chen et al. [50] studied $\mathrm{AlOOH}$ boehmite nanorods incorporated GTMS sol-gel coating. The nanorod concentration up to $40 \mathrm{wt} \%$ was utilized in the coating composition and was applied over a glass substrate. Authors recorded lower modulus and hardness values in the nanocoatings than in a commercially available coating composition containing boehmite nanoparticles. The hardness and modulus values for nanorod filled coating were $8.86 \mathrm{GPa}$ and $0.83 \mathrm{GPa}$, while those of nanoparticles filled coating were $9.88 \mathrm{GPa}$ and $0.98 \mathrm{GPa}$. The coating composition containing nanorods with an aspect ratio of approximately 20 displayed significant improvement in the crack toughness, which was achieved by incorporating nanorods with a high aspect ratio. The orientation on nanorods in the composite coating contributed to the anisotropic toughness. The enhanced toughness was considered as an outcome of the formation of chemical bonds between boehmite nanorods and the coating.

$\mathrm{Hu}$ et al. [51] studied hybrid coatings synthesized by the hydrolytic condensation of (3-methacryloxypropyl) trimethoxysilane or vinyltrimethoxysilane, with 5 - 30 $\mathrm{wt} \%$ TEOS, in the presence of formic acid. The coating of thickness between 600 and $800 \mathrm{~nm}$ was applied on glass substrate by the dip coating technique. The authors used IIT to find the hardness and modulus values of the coatings. It was noticed that coating compositions based on (3-methacryloxypropyl) trimethoxysilane and 20 - 30 wt $\%$ TEOS exhibited a $0.5 \mathrm{GPa}$ hardness value and a $0.07 \mathrm{GPa}$ brittle index.

Sakai et al. [52] used a microindentation load relaxation technique to study the linear visco-elastic stress relaxation phenomenon in sol-gel-derived phenylsilsesquioxane film coated on a soda-lime glass plate. In this study, thick coatings of approximately $20 \mu \mathrm{m}$ were used to eliminate the effect of the substrate on the measured relaxation properties. Moreover, a stepwise penetration was used on the coating until the depth of about $1.4 \mu \mathrm{m}$, followed by the load relaxation measurement as a function of time. The effects of coating processing parameters on the rheological transitions of the coatings were studied. The authors found that the evolution of silicone clusters and chain networks during the sol-gel processing stage significantly affects the rheological transitions in the coating.

Innocenzi et al. [53] prepared hybrid organic-inorganic materials from acid catalyzed sols of TEOS, GTMS, as well as titanium or zirconium alkoxides and measured the mechanical properties using Knoop microindentation and a 3 point bending test method. The modulus values calculated for the samples heated to $125^{\circ} \mathrm{C}$ for $120 \mathrm{~h}$ was found between 3 and 5 and 1 and $2 \mathrm{GPa}$ for the samples synthesized with titanium butoxide or zirconium butoxide, respectively. However, modulus values increased with an increase in heat treatment time. The fracture toughness value was in the range of $0.4-0.5 \mathrm{MPa} \cdot \mathrm{m}^{1 / 2}$ for samples treated for $168 \mathrm{~h}$ at $125^{\circ} \mathrm{C}$.

Amerio et al. [54] formulated hybrid coating by a dual curing process that combined sol-gel reaction with UV light induced polymerization. Authors incorporated bisphenol-A ethoxylate dimethylacrylate as an organic binder, methacryloxypropyl-trimethoxysilane as coupling agent and TEOS as crosslinker. The preformed silica nanoparticles were used in the formulation in place of TEOS for comparison. The coating curing procedure that employed UV light and sol-gel curing demonstrated high scratch resistance, while the composition containing pre-formed nano silica showed poor scratch resistance, severe cracking and large plastic deformations.

Douce et al. [55] performed nanoindentation experiments on silicone coatings containing various surface modified silica nanoparticles of different sizes ranging from $15 \mathrm{~nm}$ to $60 \mathrm{~nm}$. The authors found that Young's modulus of the coatings increased with the increase in silica nano-fillers. However, the scratch resistance of the coating decreased with the addition of nano-fillers, proba- 
bly due to a weak interaction between inorganic fillers and the coating network. In an interesting study Qi et al. [56] investigated the effect of hydrogen concentration on hardness of film that was prepared by reacting TEOS and methyltriethoxysilane. A significant increase in hardness was observed with the decrease in hydrogen concentration. When the film was irradiated with $\mathrm{H}^{+}$or $\mathrm{N}_{2}^{+}$, the polymerization increased with hardness value. The FTIR spectra displayed continuous decrease in -C-H band intensity that was consistence with the loss of hydrogen due to irradiations.

Robertson et al. [57] investigated the hardness and modulus value of hybrid epoxy resin composition containing TEOS and GTMS. Authors cured one composition at higher temperature while other formulation was crosslinked with amine and followed by thermal curing. They found that when coating was heated at higher temperature, the hardness value increase up to $1.6 \mathrm{GPa}$ while modulus value increased up to $15 \mathrm{GPa}$. However, coating composition containing amine crosslinker did not show significant improvement in mechanical properties even after elevated temperature curing.

Ballarre et al. [58] studies sol-gel coating that was prepared by reacting tetraethoxysilane and methyltriethoxysilane. Authors evaluated the nanomechanical properties of coating containing variable amount of silica nanoparticles. It was found from nanoindentation tests that hardness and modulus of coating increased with the increase in silica nanofillers. Moreover, scratch resistance increased on addition of $30 \mathrm{wt} \%$ nanofillers. Similarly, Nemeth et al. [59] studied the nanomechanical properties of sol-gel coating derived from glycidoxypropyltrimethoxysilane and/or methyltrimethoxysilane and containing silica nanofillers. The nanoindentation technique was utilized to evaluate the hardness and modulus values of the coating as a function of coating composition and heat treatment. It was suggested that hardness of the coating could be increased by increasing the amount of methyltrimethoxysilane in the coating composition. Moreover, significant increment in hardness was achieved in coatings that were cured to $155^{\circ} \mathrm{C}$. Hu et al. [60] studied the effect of titanium tetrabutoxide on nanomechanical properties of silsesquioxane (SSO) coating. A bilayer SSO coating was prepared by reacting GTMS, $20 \mathrm{wt} \%$ TEOS and variable amount of titanium tetrabutoxide (TTB). The nanoindentation and nanoscratch tests were performed on the two-layers that showed different hardness values for each layer. The maximum hardness value was achieved in the formulation containing $20 \mathrm{wt} \%$ TTB. The scratch tests showed inconsistent results that represented the contribution from both the layers of the coating.

The use of nanoindentation technique to determine the viscoelastic behavior of coatings is relatively new and yet to be explored in great detail [61]. Kohl et al. [62] investigated the viscoelastic properties of three proprietary silicone-based coatings using continuous indentation technique. Authors concluded that the calculated parameters would help in developing more durable silicone based foul release coating compositions

\section{Conclusions and Future Prospects}

The epoxy based coatings have been widely used in variety of applications due to the extreme tendency of epoxy group to form stable adhesive linkages. However, epoxy coatings are often associated with microporous network and therfore delaminate on exposure to moist conditions. Contrary to epoxy polymer, pure silicone coatings have dense network. However, the adhesion of such silicones is dependent on the presence of reactive functionalities such as epoxy or carboxyl groups. The studies have suggested that hybrid materials display better mechanical properties compared to the pristine polymers. It was also found that crosslinking density in hydrocarbon regime of the coating increases the stiffness in the material while crosslinking of inorganic regime increases the hardness value. Additionally, the decrease in hydrogen concentration leads to increase in hardness value in coatings. Several different nanoparticles have been used as nanofillers to increase the nanomechanical properties of the coatings. The nanoindentation hardness and modulus values are reported to increase with the addition of nanofillers. Similarly, scratch resistance and coefficient of friction also improved on addition of nanofillers. Dynamic nanoindentation could be effectively used to determine the viscoelastic properties of the coatings. Various relaxations phenomenon that appear due to the presence of nanoparticles and their interface with matrix phase could be investigated by using nanoindentation mediated dynamic mechanical analysis

\section{Acknowledgements}

Author is grateful to the director of Hawaii Corrosion Laboratory, Department of Mechanical Engineering, University of Hawaii for allowing the publication of this review article.

\section{REFERENCES}

[1] I. M. Hutchungs, "The Contributions of David Tabor to the Science of Indentation Hardness," Journal of Materials Research, Vol. 24, No. 3, 2009, pp. 581-589. doi:10.1557/jmr.2009.0085

[2] A. C. Fischer-Cripps, "Nanoindentation," 2nd Edition, In: F. F. Ling, Ed., Springer-Verlag, New York, 2004, p. 266.

[3] T. Y. TSui, C. A. Ross and G. M. Pharr, "Nanoindentation Hardness of Soft Films on Hard Substrates: Effects 
of Substrates," Materials Research Society Symposium Proceedings, Vol. 473, 1997, p. 57.

[4] S. Chen, L. Liu and T. Wang, "Investigation of the Mechanical Properties of Thin Films by Nanoindentation, Considering the Effects of Thickness and Different Coating-Substrate Combinations," Surface and Coatings Technology, Vol. 191, No. 1, 2005, pp. 25-32. doi:10.1016/j.surfcoat.2004.03.037

[5] C. Charitidis, A. Laskarakis, S. Kassavetis, C. Gravalidis, and S. Logothetidis, "Optical and Nanomechanical Study of Anti-Scratch Layers on Polycarbonate Lenses," Superlattices and Microstructures, Vol. 36, No. 1-3, pp. 171179. doi:10.1016/j.spmi.2004.08.015

[6] S. Roche, S. Pavan, J. L. Loubet, P. Barbeau and B. Magny, "Influence of the Substrate Characteristics on the Scratch and Indentation Properties of UV-Cured Clearcoats," Progress in Organic Coatings, Vol. 47, No. 1, 2003, pp. 37-48. doi:10.1016/S0300-9440(03)00017-1

[7] K. Geng, F. Yang and E. A. Grulke, "Nanoindentation of Submicron Polymeric Coating Systems," Materials Science and Engineering: A, Vol. 479, No. 1-2, 2008, pp. 157-163. doi:10.1016/i.msea.2007.06.042

[8] T. H. Zhang and Y. Huan, "Nanoindentation and Nanoscratch Behaviors of DLC Coatings on Different Steel Substrates," Composites Science and Technology, Vol. 65, No. 9, 2005, pp. 1409-1413. doi:10.1016/j.compscitech.2004.12.011

[9] X. Li and B. Bhushan, "A Review of Nanoindentation Continuous Stiffness Measurement Technique and Its Applications," Materials Characterization, Vol. 48, No. 1, 2002, pp. 11-36.

[10] M. R. VanLandingham, J. S. Villarrubia and G. F. Meyers, "Nanoindentation of Polymers: Overview," Polymer Preprints, Vol. 41, No. 2, 2000, pp. 1412-1413.

[11] J.V. Koleske, "Mechanical Properties of Solid Coatings," Encyclopedia of Analytical Chemistry, John Wiley \& Sons, Ltd., New York, 2006.

[12] F. Mammeri, E. Le Bourhis, L. Rozes and C. Sanchez, "Mechanical Properties of Hybrid Organic-Inorganic Materials," Journal of Materials Chemistry, Vol. 15, No. 35-36, 2005, pp. 3787-3811. doi:10.1039/b507309j

[13] M. R. VanLandingham, "Review of Instrumented Indentation," Journal of Research of the National Institute of Standards and Technology, Vol. 108, No. 4, 2003, pp. 249-265.

[14] A.C. FischerCripps, "Critical Review of Analysis and Interpretation of Nanoindentation Test Data," Surface and Coatings Technology, Vol. 200, No. 14-15, 2006, pp. 4153-4165. doi:10.1016/j.surfcoat.2005.03.018

[15] S. J. Bull, "Nanoindentation of Coatings," Journal of Physics D: Applied Physics, Vol. 38, No. 24, 2005, pp. R393-R413. doi:10.1088/0022-3727/38/24/R01

[16] J. L. Hay and G. M. Pharr, "Instrumented Indentation Testing," ASM Handbook, Mechanical Testing and Evaluation, ASM International, 2000, pp. 232-243.

[17] W. C. Oliver and G. M. Pharr, "An Improved Technique for Determining Hardness and Elastic Modulus Using Load and Displacement Sensing Indentation Experi- ments," Journal of Materials Research, Vol. 7, No. 6, 1992, pp. 1564-1583. doi:10.1557/JMR.1992.1564

[18] E. G. Herbert, W. C. Oliver and G. M. Pharr, "Nanoindentation and the Dynamic Characterization of Viscoelastic solids," Journal of Physics D: Applied Physics, Vol. 41, No. 7, 2008, Article ID: 074021. doi:10.1088/0022-3727/41/7/074021

[19] G. M. Odegard, T. S. Gates and H. M. Herring, "Characterization of Viscoelastic Properties of Polymeric Materials through Nanoindentation," Experimental Mechanics, Vol. 45, No. 2, 2005, pp. 130-136. doi:10.1007/BF02428185

[20] P. Davies, L. Sohier, J. Y. Cognard, A. Bourmaud, D. Choqueuse, E. Rinnert and R. Créac'hcadec, "Influence of Adhesive Bond Line Thickness on Joint Strength," International Journal of Adhesion and Adhesives, Vol. 29, No. 7, 2009, pp. 724-736. doi:10.1016/j.ijadhadh.2009.03.002

[21] X. Shi, T. A. Nguyen, Z. Suo, Y. Liu and R. Avci, "Effect of Nanoparticles on the Anticorrosion and Mechanical Properties of Epoxy Coating," Surface and Coatings Technology, Vol. 204, No. 3, 2009, pp. 237-245. doi:10.1016/j.surfcoat.2009.06.048

[22] R. S. C. Woo, H. Zhu, C. K. Y. Leung and J. K. Kim, "Environmental Degradation of Epoxy-Organoclay Nanocomposites Due to UV Exposure: Part II Residual Mechanical Properties," Composites Science and Technology, Vol. 68, No. 9, 2008, pp. 2149-2155. doi:10.1016/i.compscitech.2008.03.020

[23] X. F. Li, K. T. Lau and Y. S. Yin, "Mechanical Properties of Epoxy-Based Composites Using Coiled Carbon Nanotubes," Composites Science and Technology, Vol. 68, No. 14, 2008, pp. 2876-2881. doi:10.1016/j.compscitech.2007.10.019

[24] P. Kardar, M. Ebrahimi and S. Bastani, "Study the Effect of Nano-Alumina Particles on Physical-Mechanical Properties of UV Cured Epoxy Acrylate via Nano-Indentation," Progress in Organic Coatings, Vol. 62, No. 3, 2008, pp. 321-325. doi:10.1016/j.porgcoat.2008.01.015

[25] L. Y. L. Wu, E. Chwa, Z. Chen and X. T. Zeng, “A Study towards Improving Mechanical Properties of Sol-Gel Coatings for Polycarbonate," Thin Solid Films, Vol. 516, No. 6, 2008, pp. 1056-1062. doi:10.1016/j.tsf.2007.06.149

[26] S. Turri, L. Torlaj, F. Piccinini and M. Levi, "Abrasion and Nanoscratch in Nanostructured Epoxy Coatings," Journal of Applied Polymer Science, Vol. 118, No. 3, 2010, pp. 1720-1727.

[27] A. Tiwari, "Nanomechanical Properties of Hybrid Nanocoatings," Mechanal Engineering, University of Hawaii, Honolulu, 2011, p. 148.

[28] L. Chang, Z. Zhang, C. Breidt and K. Friedrich, "Tribological Properties of Epoxy Nanocomposites: I. Enhancement of the Wear Resistance by Nano- $\mathrm{TiO}_{2}$ Particles," Wear, Vol. 258, No. 1-4, 2005, pp. 141-148. doi:10.1016/j.wear.2004.09.005

[29] L. Chang and Z. Zhang, “Tribological Properties of Epoxy Nanocomposites: Part II. A Combinative Effect of Short Carbon Fibre with Nano-TiO 2 ," Wear, Vol. 260, No. 
7-8, 2006, pp. 869-878. doi:10.1016/j.wear.2005.04.002

[30] L. Chang, Z. Zhang, L. Ye and K. Friedrich, "Tribological Properties of Epoxy Nanocomposites: III. Characteristics of Transfer Films," Wear, Vol. 262, No. 5-6, 2007, pp. 699-706. doi:10.1016/j.wear.2006.08.002

[31] Y.-F. Zhang, S.-L. Bai, X.-K. Li and Z. Zhang, "Viscoelastic Properties of Nanosilica-Filled Epoxy Composites Investigated by Dynamic Nanoindentation," Journal of Polymer Science Part B: Polymer Physics, Vol. 47, No. 10, 2009, pp. 1030-1038. doi:10.1002/polb.21709

[32] Y.-F. Zhang, S.-L. Bai, D.-Y. Yang, Z. Zhang and S. Kao-Walter, "Study on the Viscoelastic Properties of the Epoxy Surface by Means of Nanodynamic Mechanical Analysis," Journal of Polymer Science Part B: Polymer Physics, Vol. 46, No. 3, 2008, pp. 281-288. doi:10.1002/polb.21365

[33] L. Hu, X. Zhang, Y. Sun and R. J. J. Williams, "Hardness and Elastic Modulus Profiles of Hybrid Coatings," Journal of Sol-Gel Science and Technology, Vol. 34, 2005, pp. 41-46. doi:10.1007/s10971-005-1260-1

[34] B. D. Fabes and W. C. Oliver, "Mechanical Properties of Sol-Gel Coatings," Journal of Non Crystalline Solids, Vol. 121, No. 1-3, 1990, pp. 348-356. doi:10.1016/0022-3093(90)90157-H

[35] G. W. Scherer, "Drying Gels: II. Film and Flat Plate," Journal of Non Crystalline Solids, Vol. 89, No. 1-2, 1987, pp. 217-238. doi:10.1016/S0022-3093(87)80334-4

[36] A. J. Atanacio, B. A. Latella, C. J. Barbe and M. V. Swain, "Mechanical Properties and Adhesion Characteristics of Hybrid Sol-Gel Thin Films," Surface and Coating Technology, Vol. 192, 2005, pp. 354-364. doi:10.1016/j.surfcoat.2004.06.004

[37] A. Tiwari and L. H. Hihara, "Novel Silicone Ceramer Coatings for Aluminum Protection," In: A. S. H. Makhlouf, Ed., High Performance Coatings for Automotive and Aerospace Industries, Nova Publishers, New York, 2010, p. 413.

[38] A. Tiwari and L. H. Hihara, "High Performance Reaction-Induced Quasi-Ceramic Silicone Conversion Coating for Corrosion Protection of Aluminium Alloys," Progress in Organic Coatings, Vol. 69, No. 1, 2010, pp. 16-25. doi:10.1016/j.porgcoat.2010.04.020

[39] A. Tiwari, J. Zhu and L. H. Hihara, "The Development of Low Temperature Hardening Silicone Ceramer Coatings for Corrosion Protection of Metals," Surface and Coatings Technology, Vol. 202, No. 19, 2008, pp. 4620-4635. doi:10.1016/j.surfcoat.2008.03.030

[40] S. Etienne-Calas, A. Duri and P. Etienne, "Fracture Study of Organic-Inorganic Coatings Using Nanoindentation Technique," Journal of Non-Crystalline Solids, Vol. 344, No. 1-2, 2004, pp. 60-65. doi:10.1016/j.jnoncrysol.2004.07.029

[41] S. M. Mirabedini, M. Mohseni, S. PazokiFard and M. Esfandeh, "Effect of $\mathrm{TiO}_{2}$ on the Mechanical and Adhesion Properties of RTV Silicone Elastomer Coatings," Colloids and Surfaces A: Physicochemical and Engineering Aspects, Vol. 317, No. 1-3, 2008, pp. 80-86. doi:10.1016/j.colsurfa.2007.09.044
[42] W. Tanglumlert, P. Prasassarakich, P. Supaphol and S. Wongkasemjit, "Hard-Coating Materials for Poly(Methyl methacrylate) from GlycidoxypropyltrimethoxysilaneModified Silatrane via a Sol-Gel Process," Surface and Coatings Technology, Vol. 200, No. 8, 2006, pp. 27842790. doi:10.1016/j.surfcoat.2004.11.018

[43] A. J. Atanacio, B. A. Latella, C. J. Barbé and M. V. Swain, "Mechanical Properties and Adhesion Characteristics of Hybrid Sol-Gel Thin Films," Surface and Coatings Technology, Vol. 192, No. 2-3, 2005, pp. 354-364. doi:10.1016/j.surfcoat.2004.06.004

[44] A. Ferchichi, S. Calas-Etienne, M. Smaïhi and P. Etienne, "Study of the Mechanical Properties of Hybrid Coating as a Function of Their Structures Using Nanoindentation," Journal of Non-Crystalline Solids, Vol. 354, No. 2-9, 2008, pp. 712-716.

[45] M. Esfandeh, S. M. Mirabedini, S. Pazokifard and M. Tari, "Study of Silicone Coating Adhesion to an Epoxy Undercoat Using Silane Compounds: Effect of Silane Type and Application Method," Colloids and Surfaces A: Physicochemical and Engineering Aspects, Vol. 302, No. 1-3, 2007, pp. 11-16. doi:10.1016/j.colsurfa.2007.01.031

[46] J. G. Kohl, I. L. Singer, N. Schwarzer and V. Y. Yu, "Effect of Bond Coat Modulus on the Durability of Silicone Duplex Coatings," Progress in Organic Coatings, Vol. 56, No. 2-3, 2006, pp. 220-226. doi:10.1016/j.porgcoat.2006.05.005

[47] J. G. Kohl and I. L. Singer, "Pull-Off Behavior of Epoxy Bonded to Silicone Duplex Coatings," Progress in Organic Coatings, Vol. 36, No. 1-2, 1999, pp. 15-20. doi:10.1016/S0300-9440(98)00074-5

[48] H. Kozuka, S. Takenaka, H. Tokita, T. Hirano, Y. Higashi and T. Hamatani, "Stress and Cracks in Gel-Derived Ceramic Coatings and Thick Film Formation," Journal of Sol-Gel Science and Technology, Vol. 26, No. 1, 2003, pp. 681-686. doi:10.1023/A:1020773415962

[49] J. Kim, B. J. Chisholm and J. Bahr, "Adhesion Study of Silicone Coatings: The Interaction of Thickness, Modulus and Shear Rate on Adhesion Force," Biofouling, Vol. 23, No. 1-2, 2007, pp. 113-120. doi: $10.1080 / 08927010701189708$

[50] Q. Chen, J. Tan, S. Shen, Y. Liu, W. Ng and X. Zeng, "Effect of Boehmite Nanorods on the Properties of Glycidoxypropyl-Trimethoxysilane (GPTS) Hybrid Coatings," Journal of Sol-Gel Science and Technology, Vol. 44, No. 2, 2007, pp. 125-131. doi:10.1007/s10971-007-1621-Z

[51] L. Hu, X. Zhang, Y. Sun and R. J. J. Williams, "Hardness and Elastic Modulus Profiles of Hybrid Coatings," Journal of Sol-Gel Science and Technology, Vol. 34, No. 1, 2005, pp. 41-46. doi:10.1007/s10971-005-1260-1

[52] M. Sakai, M. Sasaki and A. Matsuda, "Indentation Stress Relaxation of Sol-Gel-Derived Organic/Inorganic Hybrid Coating," Acta Materialia, Vol. 53, No. 16, 2005, pp. 4455-4462. doi:10.1016/j.actamat.2005.06.005

[53] P. Innocenzi, M. Esposto and A. Maddalena, "Mechanical Properties of 3-Glycidoxypropyltrimethoxysilane Based Hybrid Organic-Inorganic Materials," Journal of Sol-Gel Science and Technology, Vol. 20, No. 3, 2001, pp. 293301. doi:10.1023/A:1008782203971 
[54] E. Amerio, P. Fabbri, G. Malucelli, M. Messori, M. Sangermano and R. Taurino, "Scratch Resistance of NanoSilica Reinforced Acrylic Coatings," Progress in Organic Coatings, Vol. 62, No. 2, 2008, pp. 129-133. doi:10.1016/i.porgcoat.2007.10.003

[55] J. Douce, J. P. Boilot, J. Biteau, L. Scodellaro and A. Jimenez, "Effect of Filler Size and Surface Condition of Nano-Sized Silica Particles in Polysiloxane Coatings," Thin Solid Films, Vol. 466, No. 1-2, 2004, pp. 114-122. doi:10.1016/j.tsf.2004.03.024

[56] Y. Qi, T. Prenzel, T. A. Harriman, Y. Q. Wang, D. A. Lucca, D. Williams, M. Nastasi, J. Dong and A. Mehner, "Investigation of Hydrogen Concentration and Hardness of Ion Irradiated Organically Modified Silicate Thin Films," Nuclear Instruments and Methods in Physics Research Section B: Beam Interactions with Materials and Atoms, Vol. 268, No. 11-12, 2010, pp. 1997-2000. doi:10.1016/j.nimb.2010.02.116

[57] M. A. Robertson, R. A. Rudkin, D. Parsonage and A. Atkinson, "Mechanical and Thermal Properties of Organic/Inorganic Hybrid Coatings," Journal of Sol-Gel Science and Technology, Vol. 26, No. 1, 2003, pp. 291295. doi:10.1023/A:1020723821046

[58] J. Ballarre, E. Jimenez-Pique, M. Anglada, S. A. Pellice, and A. L. Cavalieri, "Mechanical Characterization of Nano-Reinforced Silica Based Sol-Gel Hybrid Coatings on AISI 316L Stainless Steel Using Nanoindentation Techniques," Surface and Coatings Technology, Vol. 203, No. 20-21, 2009, pp. 3325-3331. doi:10.1016/j.surfcoat.2009.04.014

[59] S. Nemeth and Y. C. Liu, "Mechanical Properties of Hybrid Sol-Gel Derived Films as a Function of Composition and Thermal Treatment," Thin Solid Films, Vol. 517, No. 17, 2009, pp. 4888-4891. doi:10.1016/j.tsf.2009.03.099

[60] L. Hu, D. Wang, Z. Lu, Y. Song and C. Song, "Influence of Titanium Tetrabutoxide on Nanoindentation and Nanoscratch Profiles of Silsesquioxane Films," Macromolecular Symposia, Vol. 267, No. 1, 2008, pp. 85-89. doi:10.1002/masy.200850715

[61] W. J. Wright and W. D. Nix, "Storage and Loss Stiffnesses and Moduli as Determined by Dynamic Nanoindentation," Journal of Materials Research, Vol. 24, No. 3, 2009, pp. 863-871. doi:10.1557/jmr.2009.0112

[62] J. G. Kohl, I. L. Singer and D. L. Simonson, "Determining the Viscoelastic Parameters of Thin Elastomer Based Materials Using Continuous Microindentation," Polymer Testing, Vol. 27, No. 6, 2008, pp. 679-682. doi:10.1016/j.polymertesting.2008.04.010 